\title{
Effect of flaxseed flour, grape peel and wheat gluten incorporation levels on the sensory quality of chicken meat patties
}

\begin{abstract}
Kanchan Kumari, S.S. Thind and Preety
The present investigation was planned to prepare meat patties containing flaxseed, grape peel and wheat gluten at acceptable levels and their shelf life of frozen chicken meat patties was standardized by consulting literature and by taking the opinion of taste panel members during standardization trails. Standardization of functional ingredients in chicken meat patties was done by incorporating different levels of flaxseed flour, grape peel and wheat gluten. Grape seeds were not found suitable for the incorporation in chicken meat patties on basis of organoleptic analysis. So, for further investigation only grape peel was incorporated in the preparation of chicken meat patties. Then trails of flaxseed flour was incorporated at 0, 5.0, 10.0, 15.0 and 20.0 per cent levels, grape peel at 0, 2.5, 5.0, 7.5 and 10.0 per cent levels and wheat gluten at $0,1.0,1.5,2.0,2.5$ and 3.0 per cent levels as functional ingredient in the chicken meat patties for the standardization of recipes. On the basis of sensory evaluation, best levels of flaxseed flour (5.0\%), grape peel (5.0\%) and wheat gluten $(1.5 \%)$ were selected for incorporation in final products i.e. chicken meat patties. The average scores for appearance, colour, flavour, juiciness, texture and overall acceptability decreased significantly $(\mathrm{p} \leq 0.05)$ with the increase in the frozen storage period in both conventional and vacuum packed, control and FGW chicken meat patties. The FGW chicken meat patties had a better overall acceptability as compared to control. They were more juicer, had better colour and flavour scores than the control.
\end{abstract}

Key Words : Chicken meat patties, Flaxseed flour, Grape peel, Wheat gluten conventional, Vacuum packed

How to cite this article : Kumari, Kanchan, Thind, S.S. and Preety (2020). Effect of flaxseed flour, grape peel and wheat gluten incorporation levels on the sensory quality of chicken meat patties. Food Sci. Res. J., 11(1): 8-16, DOI : 10.15740/HAS/FSRJ/11.1/ 8-16.Copyright@ 2020: Hind Agri-Horticultural Society.

Email: kanchanfst@gmail.com

Associate Authors' :

S.S. Thind and Preety, Department of Food Science and Technology, College of Agriculture, Punjab Agricultural University, Ludhiana (Punjab) India 